аспирант кафедры уголовного права и криминологии Кубанского государственного университета

\section{ПРОБЛЕМЫ ПРЕСТУПНОСТИ НЕСОВЕРШЕННОЛЕТНИХ ЛИЦ, ОБУСЛОВЛЕННЫЕ ВОВЛЕЧЕНИЕМ ИХ В СОВЕРШЕНИЕ ПРЕСТУПЛЕНИЙ И АНТИОБЩЕСТВЕННЫХ ДЕЙСТВИЙ: УГОЛОВНО-ПРАВОВЫЕ АСПЕКТЫ И МЕТОДЫ БОРЬБЫ С ПРОТИВОПРАВНЫМ ПОВЕДЕНИЕМ НЕСОВЕРШЕННОЛЕТНИХ НА ПРИМЕРЕ РЕСПУБЛИКИ КАЛМЫКИЯ}

\section{Аннотация:}

В статье рассматриваются проблемы вовлечения несовершеннолетних граждан в совершение преступлений $и$ антиобщественных действий, а именно причины противоправного поведения подростков. Проводится анализ состояния преступности несовершеннолетних за последние несколько лет, сравниваются показатели преступности несовершеннолетних по Республике Калмыкия с другими субъектами Российской Федерации. Исследуется комплекс мер, направленных на предупреждение преступных деяний и антиобщественных действий данной категории лии, применяемых правоохранительными органами Республики Калмыкия. Уголовно-правовая борьба с преступностью несовершеннолетних, вовлечением их в общественно опасные преступные деяния и совершение антиобщественных действий - одна из важнейших целей государственных органов в сфере защиты прав и интересов несовершеннолетних лиц. Разработка эффективных уголовно-правовых мер и средств является первоочередной задачей в борьбе с вовлечением в преступную деятельность несовершеннолетних. Состояние преступности на территории Республики Калмыкия является своего рода показателем эффективности деятельности надзорных органов по предупреждению преступности несовершеннолетних лиц. Показатели носят неоднозначный характер, что говорит о недостаточной эффективности деятельности надзорноконтрольных органов. Перед разработкой и применением комплекса профилактических и предупредительных мер, применяемых к несовершеннолетним, правоохранительным органам прежде всего необходимо выявить причины и факторы противоправного и асоциального поведения. Автор предлагает применить комплекс усовершенствованных средств и профилактических мер, направленных на снижение и предотвращение совершения преступлений и антиобщественных действий несовершеннолетними на территории Республики Калмыкия.

Ключевые слова:

преступные деяния, антиобщественные действия, предупреждение, меры профилактики, противоправное поведение подростков, снижение уровня преступности среди несовершеннолетних, Республика Калмыкия.
PhD student, Criminal Law and Criminal Studies Department, Kuban State University

THE PROBLEMS OF JUVENILE DELINQUENCY DUE

TO THE INVOLVEMENT OF MINORS IN CRIMES AND ANTISOCIAL ACTIONS: CRIMINAL AND LEGAL ASPECTS AND METHODS OF DEALING WITH JUVENILE OFFENDING BEHAVIOR BY A CASE STUDY OF THE REPUBLIC OF KALMYKIA

Summary:

The study discusses the problems of involving the minors in crimes and antisocial actions, namely the reasons for offending behavior of adolescents. The research analyzes juvenile delinquency over the past few years and compares juvenile crime rates in the Republic of Kalmykia with ones in other constituent entities of the Russian Federation. The paper investigates a set of measures aimed at preventing crimes and antisocial actions of this category of persons used by law enforcement agencies of the Republic of Kalmykia. The criminal legal fight against juvenile delinquency, involvement of minors in crimes that can affect society and antisocial actions is one of the most important objectives of the public authorities in the field of protection of the juvenile rights and interests. The development of effective criminal law measures and tools is a priority in the fight against the involvement of minors in criminal activities. The crime rate in the Republic of Kalmykia demonstrates the effective/ineffective activities of the supervisory authorities intended to prevent juvenile delinquency. The ambiguous rates show the lack of effectiveness of supervisory and control bodies. Prior to the development and implementation of the set of preventive and precautionary measures applicable to minors, law enforcement authorities must first identify the causes and factors of illegal and antisocial behavior. The author proposes to apply a range of advanced tools and preventive measures designed to reduce and prevent juvenile crimes and antisocial actions in the territory of the Republic of Kalmykia.
Keywords: crimes, antisocial actions, prevention, preventive measures, illegal behavior of adolescents, reducing juvenile delinquency, Republic of Kalmykia. 
В Российской Федерации несовершеннолетние лица являются одной из категорий населения, которые подлежат особой защите со стороны государства. Именно поэтому приобретают актуальность законодательное закрепление их прав и их защита на максимально высоком уровне [1]. Проблема преступности несовершеннолетних - одна из главных существующих проблем.

Предпосылки совершения преступных деяний лицами, которые не достигли 18-летнего возраста, обусловлены разными взаимосвязанными причинами, в частности отсутствием должного воспитания и контроля со стороны родителей, попечителей, опекунов (включая неблагоприятный климат в семье, асоциальность родителей и т. п.), влияние преступных элементов, социально-экономического развития региона и др.

Происходящие в России социально-экономические преобразования вызвали такие негативные тенденции, как нарастание процессов деформации семьи, резкое снижение востребованности духовных ценностей, разительное имущественное неравенство населения, безработица, осложнение криминальной обстановки, что, несомненно, повлияло на состояние людей. В частности, на эмоциональном уровне происходящие изменения порождают у граждан недоверие, неприятие и агрессию по отношению к окружающим. Путем насилия люди пытаются найти решение создавшихся проблем, что не может не отразиться на подрастающем поколении, на миропонимании детей и подростков, которое неизбежно деформируется и в дальнейшем отрицательно влияет на их жизнь [2].

Важно отметить, что совершение преступлений несовершеннолетними гражданами обусловлено процессом их вовлечения в противоправную деятельность, которая выражается в понуждении и подстрекательстве к противоправным действиям, которые в конечном итоге и приводят к совершению преступного деяния.

Вовлечение несовершеннолетних в совершение преступных деяний урегулировано нормами ст. 150 УК РФ, антиобщественных действий - ст. 151 УК РФ [3]. Преступными действиями признаются действия определенных лиц, закрепленных законом, направленные на возбуждение желания совершить преступление, используя обман, угрозы и пр., к антиобщественным действиям законодатель относит распитие спиртных напитков, употребление одурманивающих веществ, попрошайничество и бродяжничество.

Противоправное поведение подростков обусловлено в первую очередь вышеназванными действиями, которые негативным образом влияют на личность, разрушают и извращают ее качества и свойства, нарушают устои общества и нормы права.

В ст. 421 УПК РФ закреплено, что по делам несовершеннолетних обязательно устанавливается влияние на них старших по возрасту лиц [4]. Как правило, взрослые лица, ведущие асоциальный образ жизни, нарушающие законы, сознательно передают отрицательный опыт, взращивая в несовершеннолетних гражданах нетерпимость к установленным нормам права.

Противодействие вовлечению несовершеннолетних лиц в совершение преступлений и иных антиобщественных действий является важнейшим направлением предупреждения противоправного поведения указанной категории лиц. Нейтрализация негативного влияния на несовершеннолетних со стороны взрослых - одна из главных задач правоохранительных органов.

Рассмотрим периоды, во временных пределах которых преступления совершались несовершеннолетними категориями граждан.

Согласно офрицильным данным Федеральной службы государственной статистики по вопросу состояния преступности несовершеннолетних в Российской Федерации в I квартале 2018 г. число несовершеннолетних лиц, совершивших преступления, составило 1,2 тыс. человек. По сравнению с периодом 2017 г. уровень совершения преступных деяний лицами, не достигшими 18-летнего возраста, снизился на 2,2 \% [5].

Если проводить сравнительный анализ уровня преступности несовершеннолетних за период 2014-2018 гг. по Республике Калмыкия, то стоит отметить, что в 2014 г. на территории Калмыкии было зарегистрировано 62 преступления, совершенных подростками от 14 до 18 лет (что составило 42 \%). В 2015 г. уровень преступности несовершеннолетних снизился на 40,3 \% (с 62 до 37) [6].

Генеральной прокуратурой Российской Федерации были опубликованы данные о преступности несовершеннолетних лиц в субъектах России за январь - ноябрь 2017 г., в частности в Калмыкии указанными лицами было совершено 44 преступления [7].

По официальным данным информационного портала Калмыкии, в республике за 2017 г. сотрудниками подразделения по делам несовершеннолетних министерства внутренних дел Республики Калмыкия (далее - ПДН МВД РК) было проведено 737 рейдовых мероприятий, в результате которых было выявлено 68 несовершеннолетних лиц, которые находились в состоянии алкогольного опьянения, 2 человека - в наркотическом. К ответственности, установленной Кодексом Российской Федерации об административных правонарушениях от 30 декабря 2001 г. № $195-$ 
Ф3, был привлечен 321 родитель за ненадлежащее исполнение своих обязанностей по содержанию и воспитанию несовершеннолетних; на профилактическом учете состояли 130 несовершеннолетних лиц и 83 родителя (попечителя, опекуна).

В соответствии с данными Прокуратуры Республики Калмыкия за январь - февраль 2018 г., в Республике Калмыкия несовершеннолетними было совершено 11 преступлений (в 2017 г. - 1 преступление), что составляет более 1000 \% [8].

Важно указать, что преступления на территории Калмыкии совершались подростками в результате длительного процесса вовлечения их в совершение антиобщественных действий (употребление алкоголя и наркотических средств) и отсутствия необходимого воспитания, что привело к такому результату.

В целом складывается неоднозначная ситуация с годовыми показателями преступности несовершеннолетних в Калмыкии, однако республика остается регионом с самым низким уровнем преступности.

Что касается остальных регионов, то по показателям 2016 г. Республика Ингушетия являлась лидером среди регионов с самым низким показателем преступлений, совершенных несовершеннолетними гражданами, - всего 5 преступлений. В Чеченской Республике количество таких преступлений достигло 21, а на Чукотке и в Ямало-Ненецком автономном округе - 26 и 51 соответственно.

Регионами с самым высоким уровнем преступности остаются Свердловская, Магаданская, Челябинская области, Красноярский край.

Анализируя приведенные данные, стоит отметить, что регионами с низкими показателями являются непосредственно субъекты РФ - республики. Соответственно, можно предположить, что уровень преступности зависит в том числе от уровня национальной культуры, традиций, духовно-нравственного воспитания и работы правоохранительных органов, а не только от социально-экономического развития. Указанные республики не являются лидерами по экономическим показателям. Так, в рейтинге социально-экономического положения субъектов РФ за 2016 г. Калмыкия занимала 82-е место из 85, Ингушетия - 80-е [9].

Конечно, уровень экономического благополучия напрямую влияет на преступность, но, как показало исследование, более не является главным фрактором. Приведенные данные свидетельствуют о неоднозначной эффективности действий, которые применяют правоохранительные органы для снижения уровня преступности среди несовершеннолетних граждан.

Проблема вовлечения подростков в совершение преступных деяний и антиобщественных действий характеризуется несколькими моментами.

- Желание подростка стать старше, равняться на взрослого (как правило, к противоправному действию склоняет взрослое асоциальное лицо).

- Извращенная правовая информированность взрослых лиц о смягчении наказания либо его избежании в случае совершения преступления несовершеннолетними лицами (исходят из того, что последние не подлежат уголовной ответственности в силу возраста и пр.).

- Антиобщественные настроения (сознательные желания взрослого населения разрушить общество, внести хаос).

- Отсутствие должного воспитания, нахождение ребенка в «разрушенной ячейке общества».

Отметим, что главным фактором рассматриваемой проблемы остается фрактор влияния взрослой категории населения на несовершеннолетних.

Предупреждение совершения преступлений и антиобщественных действий несовершеннолетними - основная задача подразделений по делам несовершеннолетних как на фредеральном, так и на региональном уровне.

Систему комиссий в Республике Калмыкия составляют:

1) комиссия по делам несовершеннолетних и защите их прав Республики Калмыкия;

2) комиссии по делам несовершеннолетних и защите их прав в муниципальных образованиях Республики Калмыкия [10].

В Республике Калмыкия ПДН МВД РФ по РК является государственным органом. Основными задачами Комиссии ПДН как его структурного подразделения являются:

1) предупреждение безнадзорности, беспризорности, правонарушений и антиобщественных действий несовершеннолетних, выявление и устранение причин и условий, способствующих этому;

2) обеспечение защиты прав и законных интересов несовершеннолетних;

3) социально-педагогическая реабилитация несовершеннолетних, находящихся в социально опасном положении, в том числе связанном с немедицинским потреблением наркотических средств и психотропных веществ;

4) выявление и пресечение случаев вовлечения несовершеннолетних в совершение преступлений и антиобщественных действий [11]. 
Республиканская комиссия, в частности, координирует деятельность органов и учреждений системы профилактики, осуществляет мониторинг их деятельности в пределах и порядке, установленных законодательством Российской Федерации и Республики Калмыкия; разрабатывает и вносит в Правительство Республики Калмыкия предложения по осуществлению мероприятий в области защиты прав несовершеннолетних, профилактики их безнадзорности и правонарушений; оказывает методическую помощь, осуществляет информационное обеспечение и контроль за деятельностью муниципальных комиссий в соответствии с законодательством Республики Калмыкия; участвует в разработке проектов нормативных правовых актов Республики Калмыкия, направленных на профилактику безнадзорности, беспризорности, алкоголизма, наркомании и правонарушений несовершеннолетних, реабилитацию и ресоциализацию несовершеннолетних, допускающих немедицинское потребление наркотических средств и психотропных веществ, защиту семьи с несовершеннолетними детьми, анализируют их эффеективность [12].

Известно, что материнство и детство, семья находятся под защитой государства [13]. Для того чтобы пресечь процессы вовлечения несовершеннолетних граждан в совершение преступлений, по нашему мнению, необходимо своевременно выявлять криминогенные факторы, а также лиц, понуждающих и подстрекающих подростков совершать различного рода преступления. Под воздействием асоциальной категории лиц несовершеннолетний ввиду неокрепшей психики повторяет действия и поступки, впитывает информацию, которая отрицает позитивные общественные нормы, носит преступный и противозаконный характер.

Вовлечение несовершеннолетних в преступления и антиобщественные действия носит длительный процесс, поэтому следственным органам следует применить максимально возможные меры для его выявления, а именно: установить круг общения несовершеннолетних, дать оценку их интересам и образу жизни, определить психологический климат в семье, опросить свидетелей, изучить обстоятельства, при которых несовершеннолетний гражданин мог преступить закон или его действия находились на грани дозволенности, установленной уголовным законом.

Более того, для возбуждения уголовного дела по ст. 150-151 УК РФ следователям необходимо подробнее рассматривать сообщения, заявления, жалобы граждан на противоправное поведение подростков, изучить материал подразделений по вопросу предупреждения групповых нарушений закона несовершеннолетними, а также преступных деяний, которые совершаются ими совместно со взрослыми (совершеннолетними) гражданами, анализировать данные журналов учета неблагополучных семей, которые состоят на учете ПДН.

Также в целях пресечения процесса вовлечения правоохранительными органами субъектов РФ необходимо усовершенствовать меры профилактики и предупреждения преступности несовершеннолетних. Так, следует:

- повысить эффективность контроля и надзора за неблагополучными семьями путем ограждения несовершеннолетних от отрицательного воздействия со стороны взрослых членов семьи. Это говорит о том, что надзорные органы обязаны разработать программу незамедлительных действий даже при однократном поступлении сведений об отрицательном поведении лиц, имеющих несовершеннолетних детей (например, скандалы, распитие спиртных напитков и т. п.). Работа с неблагополучными семьями, в частности учет и контроль родителей и детей из таких семей, должна вестись очень серьезно, так как существующая система мер ответственности взрослых не меняет их отношения к своим детям и их будущему [14];

- проводить воспитательные и показательные беседы с представителями интересов, прав, свобод несовершеннолетних - родителями, попечителями, опекунами. Контрольно-надзорным органам необходимо визуализировать различные ситуационные модели, а также указывать на последствия негативного поведения несовершеннолетних граждан;

- осуществлять взаимодействие органов ПДН с правоохранительными органами для выявления лиц, оказывающих негативное влияние на подростков, а также вовлекающих их в противоправные асоциальные деяния;

- пропагандировать здоровый образ жизни, вовлекать несовершеннолетних в спортивные и культмассовые, театральные, художественные и танцевально-хореографические секции и кружки;

- проводить в рамках образовательных учреждений различные научные мероприятия и конференции, возбуждающие интерес к наукам, технике и технологиям, робототехнике и способствующие развитию мышления подростка. Указанные мероприятия должны занимать большую часть свободного времени подростка;

- повышать уровень духовно-нравственного воспитания среди лиц подросткового возраста, а именно проводить профилактические беседы, показывать документальные фильмы в общеобразовательных учреждениях об антисоциальных явлениях и ответственности за их совершение; 
- пропагандировать правомерное поведение и необходимость правовой информированности (проведение благотворительных мероприятий, бесед о помощи незащищенным категориям лиц и т. п.);

- тщательно изучить личность несовершеннолетних, их наклонности, выявлять их на этапе «взращивания»;

- организовывать трудовые места для несовершеннолетних;

- создавать учреждения и организации, осуществляющие обучение различным полезным навыкам и ремеслу (например, исходя из характера республики как сельскохозяйственного региона - ковроткачество, вязание, национальная кулинария и т. п.);

- пропагандировать национальную культуру и игры (например, в Республике Калмыкия популярны проведение игр в альчики, концертов калмыцкой песни и танца (народного фольклора), чтение калмыцких сказаний, эпоса «Джангр», воспитание любви к калмыцкому языку и национальным традициям).

Семья как основная ячейка общества должна оказывать поддержку своим детям, находиться в постоянной духовной связи с ними, рассказывать о толерантности по отношению к окружающим и позитивным явлениям (культуре), воспитать отторжение к противоправным процессам.

Во всех действиях в отношении детей, независимо от того, предпринимаются они государственными или частными учреждениями, занимающимися вопросами социального обеспечения, судами, административными или законодательными органами, первоочередное внимание уделяется наилучшему обеспечению интересов ребенка (ст. 3 Конвенции о правах ребенка) [15].

Вовлечение несовершеннолетних лиц в совершение преступлений и антиобщественных действий на территории Республики Калмыкия в целом характеризуется низкой тенденцией к росту. Надзорные органы осуществляют контроль над вышеописанными процессами, региональные органы государственной власти формируют законодательную базу и различные методики, цель которых - предупредить совершение преступлений на территории Калмыкии несовершеннолетними.

Для криминологической науки изучение вопросов вовлечения несовершеннолетних в преступную деятельность является необходимым, так как она представляет собой резерв всей последующей преступности в целом. Большой процент рецидивистов, на наш взгляд, совершили свое первое преступление, не достигнув совершеннолетия. Увеличение преступности несовершеннолетних граждан ухудшает ее характер. Соответственно, ее анализ и разработка эффрективных мер позволят нейтрализовать криминогенные фракторы в социуме, сформировать базу для прогноза преступности и усовершенствовать меры противодействия.

Таким образом, формирование личности подростка происходит под влиянием воспитательных мер, семейных и общечеловеческих ценностей и традиций, основная цель которых донести полезную духовно-нравственную информацию о различных общественных явлениях, в том числе о законе, понятии преступления и наказания за его совершение.

Преступные элементы способны оказать влияние на несформировавшуюся личность, внушить ей асоциальные установки, извратить истинное представление о явлениях общества и способах взаимодействия с ним.

Органам государственной власти, органам местного самоуправления необходимо выработать методику и избрать политику, направленную на своевременное выявление негативного воздействия и повышение культуры правомерного поведения среди лиц 14-18 лет. Перечисленные меры, по нашему мнению, способны до минимума снизить уровень преступности среди подростков.

Законодательные органы власти, министерства и ведомства, структурные подразделения, общественные организации, созданные в Российской Федерации, должны усовершенствовать существующие меры по предупреждению рассматриваемой в статье проблемы.

\section{Ссылки и примечания:}

1. Веденкина Л.В. Борьба с вовлечением несовершеннолетних в преступную или иную антиобщественную деятельность - проблема государственная // Вестник Южно-Уральского государственного университета. Серия: Право. 2011. № 19. C. 24-26.

2. Cox P. History and Global Criminology: (Re)Inventing Delinquency in Vietnam // British Journal of Criminology. 2012. Vol. 52, no. 1. P. 17-31. https://doi.org/10.1093/bjc/azr061 ; Chmielowiec J., Rajewski A. Health Politics and Strategies of Action against Drug Addiction in European Countries and the States // Family Medicine and Primary Care Review. 2012. Vol. 14, no. 1. P. 97-102.

3. Уголовный кодекс Российской Федерации от 13 июня 1996 г. № 63-Ф3 // Собрание законодательства Российской Федерации. 1998. № 22. Ст. 2332.

4. Уголовно-процессуальный кодекс Российской Федерации от 18 дек. 2001 г. № 174-Ф3 : ред. от 23 апр. 2018 г. // Собрание законодательства Российской Федерации. 2002. № 22. Ст. 2027.

5. По данным официальной статистики об уровне преступности несовершеннолетних за период 2014-2018 гг. См.: Федеральная служба государственной статистики [Электронный ресурс]. URL: http://www.gks.ru/ (дата обращения: 25.04.2018). 
6. Прокуратурой Республики Калмыкия проведен анализ состояния преступности среди несовершеннолетних в 2015 г. и принимаемых мер по профилактике безнадзорности и правонарушений среди этой категории [Электронный ресурс] // Прокуратура Республики Калмыкия. 2016. 14 марта. URL: http://www.kalmprok.ru/news/4600-prokuraturoj-respubliki-kalmykiya-proveden-analiz-sostoyaniya-prestupnosti-sredi-nesovershennoletnikh-v-2015-godu-i-prinimaemykh-merpo-profilaktike-beznadzornosti-i-pravonarushenij-sredi-etoj-kategorii (дата обращения: 27.04.2018).

7. Генеральная прокуратура Российской Федерации [Электронный ресурc]. URL: https://genproc.gov.ru (дата обращения: 27.04.2018).

8. Основные показатели состояния преступности в Республике Калмыкия за январь - февраль 2018 г. [Электронный ресурс] // Прокуратура Республики Калмыкия. 2018. 12 марта. URL: http://www.kalmprok.ru/stat/5960-osnovnye-pokazateli-sostoyaniya-prestupnosti-v-respublike-kalmykiya-za-yanvar-fevral-2018-goda (дата обращения: 27.04.2018).

9. Рейтинг социально-экономического положения субъектов РФ. Итоги 2016 г. [Электронный ресурс] // РИА Рейтинг. 2017. 30 мая. URL: http://vid1.rian.ru/ig/ratings/rating_regions_2017.pdf (дата обращения: 05.05.2018).

10. О комиссии по делам несовершеннолетних и защите их прав в Республике Калмыкия : закон Республики Калмыкия от 18 нояб. 2014 г. № 78-Ф3 // Хальмг унн. 2014. № 206.

11. Там же.

12. О комиссии по делам несовершеннолетних и защите их прав Республики Калмыкия [Электронный ресурс] : постановление Правительства Республики Калмыкия от 10 февр. 2015 г. № 51 // Там же. URL: http://kalmykia.regnews.org/doc/nq/2r.htm (дата обращения: 06.05.2018).

13. Конституция Российской Федерации от 12 дек. 1993 г. : с изм. на 21 июля 2014 г. // Российская газета. 1993. 25 дек. № 237.

14. Корягина С.А. Юридические основы противодействия вовлечению несовершеннолетних в преступную деятельность [Электронный ресурс] // Baikal Research Journal. 2013. № 1. URL: http://brj-bguep.ru/reader/article.aspx?id=18691 (дата обращения: 14.06.2018).

15. Конвенция о правах ребенка : одобрена Генеральной Ассамблеей ООН 20 нояб. 1989 г. : вступ. в силу для СССР 15 сент. 1990 г., ратифицирована Постановлением ВС СССР от 13 июня 1990 г. № 1559-І.

\section{References:}

Chmielowiec, J \& Rajewski, A 2012, 'Health Politics and Strategies of Action against Drug Addiction in European Countries and the States', Family Medicine and Primary Care Review, Vol. 14, no. 1, pp. 97-102.

Cox, P 2012, 'History and Global Criminology: (Re)Inventing Delinquency in Vietnam', British Journal of Criminology, Vol. 52, no. 1, pp. 17-31. https://doi.org/10.1093/bjc/azr061.

Koryagina, SA 2013, 'Legal basis for counteracting the involvement of minors in criminal activity', Baikal Research Journal, No. 1, viewed 14 June 2018, <http://brj-bguep.ru/reader/article.aspx?id=18691>, (in Russian).

Vedenkina, LV 2011, 'Combating the involvement of minors in criminal or other antisocial activities as a public problem', Vestnik Yuzhno-Ural'skogo gosudarstvennogo universiteta. Seriya: Pravo, No. 19, pp. 24-26, (in Russian). 